\title{
Experiência de fluxo na prática e aprendizagem musical
}

\author{
Rosane Cardoso de Araújo* \\ Universidade Federal do Paraná
}

\section{Resumo:}

A Teoria do Fluxo de Csikszentmihalyi (2003, 1999, 1996, 1992, 1990) pode ser considerada como referencial significativo para os estudos sobre motivação e prática musical. De acordo com este autor, o envolvimento do sujeito de forma intensa numa determinada atividade pode gerar a experiência de fluxo, caracterizada como um momento de imersão total numa atividade compatível com as habilidades do sujeito que leva uma excelente sensação de bem estar, a ponto de alterar a percepção do tempo. Este processo, se constante, favorece a aquisição da personalidade autotélica, perfil caracterizado pelo aumento da capacidade de concentração auto-estima e satisfação. A teoria do fluxo tem sido utilizada em pesquisas sobre cognição, aprendizagem e performance musical e muitos resultados significativos estão sendo apontados.

Palavras-chave: Teoria do Fluxo; experiência de fluxo; motivação e música

* Rosane Cardoso Araújo, Doutora em Música. Professora do Departamento de Artes/UFPR, onde atua nos cursos de Graduação em Música e no curso de Mestrado em Música. Coordenadora do Programa de Pós-Graduação em Música/UFPR. Desenvolve pesquisa nas áreas de Cognição e Educação Musical. Diretora Regional (Região Sul) da Associação Brasileira de Educação Musical - ABEM. 


\section{Introdução}

A motivação orienta todo o tipo de atividade humana por meio de fatores intrínsecos e/ou extrínsecos que asseguram ao ser humano a qualidade da persistência e do direcionamento da atenção para o desenvolvimento de suas tarefas. Assim, nos estudos sobre motivação e aprendizagem, diferentes enfoques têm sido considerados com o objetivo de compreender processos motivacionais que envolvem o indivíduo na execução das mais diversas tarefas. Deci e Ryan (2000), por exemplo, buscam associar, em seus estudos sobre motivação, os resultados catalisadores que favorecem o crescimento pessoal e que geram indivíduos mais automotivados, integrados em determinadas situações que outros, a partir da observação de evidências na relação entre as especificidades de determinados sujeitos e o contexto social no qual se inserem. Costa e Boruchovitch (2008) esclarecem também que em muitos estudos sobre motivação são observadas as definições das metas, os propósitos e os direcionamentos do comportamento humano, para avaliar as escolhas e a persistência dos sujeitos em suas atividades.

40 Existe, portanto, inúmeras possibilidades de verificar ou analisar processos motivacionais desenvolvidos nas diversas atividades realizadas pelos indivíduos. Tais possibilidades de análise são foco de diferentes teorias sobre motivação. Bzuneck (2001), tratando das pesquisas sobre motivação na aprendizagem, observa que estas têm sido desenvolvidas especialmente na área da Psicologia, relacionando, portanto, motivação no trabalho mental, isto é, num processo cognitivo. Dentre as várias abordagens atuais dos estudos sobre motivação, se pode destacar como exemplo os estudos sobre autodeterminação, expectativa-valor, auto-eficácia, auto-regulação e teoria do fluxo.

Também os estudos sobre processos motivacionais presentes na aprendizagem e prática musical têm revelado resultados que podem auxiliar músicos e educadores a compreender aspectos do investimento pessoal dos sujeitos e o grau de envolvimento ativo destes nas tarefas realizadas, bem como 
refletir sobre a qualidade de tal envolvimento e as conseqüências e resultados das atividades musicais na relação entre motivação intrínseca e extrínseca. Dentre os objetos que podem ser focalizados pelas pesquisas sobre motivação para a aprendizagem e prática musical, encontram-se estudos que se relacionam a diferentes teorias que tratam sobre o uso de estratégias; qualidade de empenho e sua relação nos resultados; desenvolvimento social; concentração; crenças de auto-eficácia; autodeterminação; e experiência de fluxo, entre outros.

Neste texto, portanto, é destacada especialmente a teoria do fluxo desenvolvida por Csikszentmihalyi (2003, 1999, 1996, 1992, 1990), explorada em pesquisas de diferentes áreas (Abrantes, 2007; Campeiz; Volp, 2004; Volp; Deutsch; Schwartz, 1995) e também na área de música, especialmente em pesquisas sobre cognição, aprendizagem e performance musical (Griffin, 2008; Custodero, 2006; Addessi; Pachet, 2007; O’Neill, 1999; Silva 2008; Troum 2008; Araújo; Pickler, 2008).

Csikszentmihalyi explica que o indivíduo, ao prestar atenção em uma determinada tarefa, direcionado por metas, mantém sua atenção e vincula-se a um processo de motivação. Neste sentido as intenções e a motivação são identificadas como manifestações que auxiliam a concentração da energia psíquica, criando uma ordem na consciência e um empenho extraordinário do indivíduo na realização de uma atividade. Ao tratar sobre este processo, o autor desenvolve a teoria do fluxo, que trata sobre a qualidade do envolvimento do sujeito na realização de uma atividade específica.

\section{Experiência de fluxo}

Na Teoria do Fluxo (ou Flow Theory). Csikszentmihalyi (1999, 1992, 1990) aborda aspectos relacionados à experiência vivida pelos indivíduos altamente motivados, e conseqüentemente determinados na realização de suas atividades, cujo envolvimento é qualitativamente intenso e emocionante. $\mathrm{O}$ autor explica que o "estado de fluxo" é gerado a partir de componentes afetivos da motivação vinculados à motivação intrínseca e à concentração, que direcionam a 
execução de uma atividade. O estado de fluxo, portanto, pode ser caracterizado como um profundo envolvimento pessoal nas atividades de forma exclusiva, aplicada e prazerosa.

Segundo Csikszentmihalyi (1999), o fluxo ocorre quando o indivíduo está totalmente envolvido, imerso, numa atividade que the proporciona desafio, no limiar de suas capacidades de controle. Ele explica: "Experiências ótimas geralmente envolvem um fino equilíbrio entre a capacidade do indivíduo de agir e as oportunidades disponíveis para ação" (p. 37).

Para o autor, o estabelecimento de metas é o primeiro passo para que em seguida o indivíduo possa seguir para uma etapa de concentração. A concentração do sujeito, por sua vez, pode gerar o estado de fluxo, desde que sejam mantidos desafios possíveis à sua capacidade. Assim, se os desafios estão além das possibilidades do sujeito, acabam causando a ansiedade, a preocupação e conseqüentemente a frustração. Do mesmo modo, se os desafios estão abaixo das habilidades e capacidades do indivíduo, podem causar o relaxamento e por conseqüência a apatia, o tédio, enfim, o desinteresse. Segundo Csikszentmihalyi (1999), é necessário que os desafios sejam enfrentados num contexto de equilíbrio entre desafios e habilidades do envolvido. Neste caso, o

42 comprometimento profundo da pessoa com a atividade possui uma alta probabilidade de gerar o fluxo; isto é, um determinado estado, de envolvimento total com o que se está fazendo, que mantém a mente concentrada a ponto de proporcionar a perda da noção de tempo, sensação de bem estar, alegria (ver Gráfico 1). 


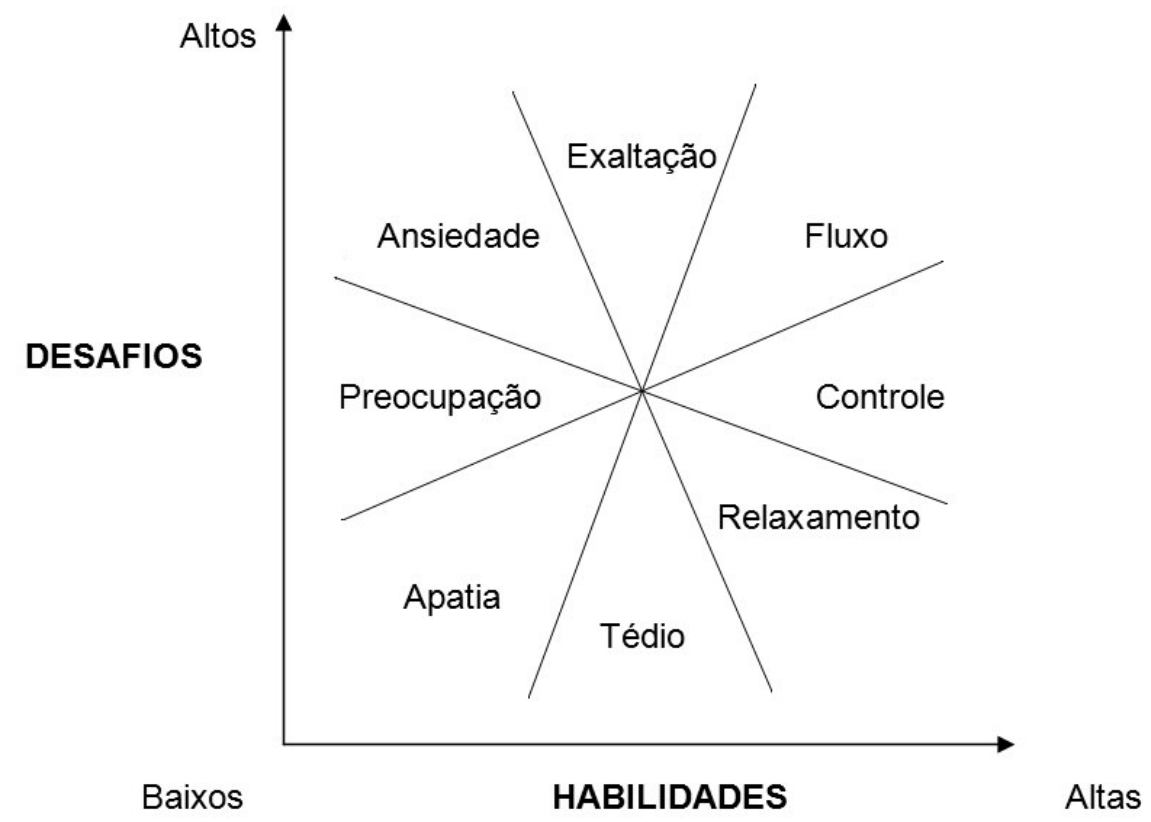

Gráfico 1 Relação entre desafios e habilidades para o processo do fluxo (Fonte: Csikszentmihalyi, 1999, p. 38)

O indivíduo que se encontra no estado de fluxo, ou seja, numa situação de equilíbrio entre os desafios e habilidades, tem sua energia psíquica totalmente focalizada e concentrada na atividade executada. Neste sentido, não há espaço na consciência para sentimentos externos ao foco da atividade ou para pensamentos diversos. Nesse contexto de perfeita harmonia entre energia física e psíquica, a noção de tempo torna-se alterada, de forma que o indivíduo passa a não ter uma percepção real do tempo ("horas tornam-se minutos”).

Para Cszikszentmihalyi, alguns conteúdos acompanham a experiência do fluxo, como a emoção, as metas e as operações mentais (operações cognitivas). Estes conteúdos são descritos como "conteúdos da experiência" que se tornam inter-relacionados para que o fluxo seja gerado.

Segundo Csikszentmihalyi (1999), os fatores de equilíbrio e as atividades que levam o sujeito a experimentar constantemente a experiência do fluxo em sua vida geram o que o autor chama de "personalidade autotélica"; ou seja, uma personalidade que favorece ao indivíduo enfrentar as situações de sua vida de 
forma entusiástica e envolvente. Esta atitude, portanto, diz respeito ao próprio significado da expressão "experiência autotélica”, que, segundo Silva (2007), é identificada como uma experiência intensa, valorosa para o indivíduo, realizada sem uma conseqüência externa ou um estímulo externo ao sujeito. Para este autor, as atitudes criativas estão vinculadas a este conceito.

Csikszentmihalyi (1999) e Silva (2007) apontam para a personalidade autotélica - consumada pela incidência das experiências no estado fluxo - como uma característica de indivíduos movidos especialmente pela motivação intrínseca, enquanto que a atitude contrária, ou exotélica, apontaria para uma ação motivada por fatores extrínsecos. Na experiência autotélica desenvolvida pelos sujeitos especialmente durante as situações desafiadoras, alguns fatores podem ser considerados constituintes desta experiência, como a concentração, satisfação, felicidade e auto-estima.

O conceito de "experiência de fluxo" desenvolvido por Csikszentmihalyi já foi utilizado em pesquisas na área da música, especialmente nas linhas da cognição, aprendizagem e prática musical. Como estudos recentes, que se utilizaram da teoria do fluxo como referencial para suas pesquisas, são apresentados neste texto os trabalhos de Griffin (2008), Custodero (2006), Addessi e Pachet (2007), Silva (2008), Troum (2008), O’ Neill (1999) e Araújo e Pickler (2008). Os resultados de tais estudos favorecem o reconhecimento da relação entre os elementos apontados nesta teoria e a aplicação destes na otimização da experiência musical.

\subsection{Emoção}

As emoções são descritas pelo autor como os elementos mais subjetivos da consciência ao mesmo tempo em que são os conteúdos mais objetivos da mente, pois traduzem muitas vezes sensações físicas: “[...] a sensação física que experimentamos quando estamos apaixonados, envergonhados, felizes é geralmente mais real para nós do que aquilo que experimentamos no mundo 
exterior [....]" (Cszikszentmihalyi, 1999, p. 25). As emoções são consideradas como estados interiores de consciência.

Cszikszentmihalyi $(1990,1999)$ explica que as emoções negativas como ansiedade, tédio, medo, tristeza produzem na mente do sujeito o que o autor define como "entropia psíquica", que é um estado no qual o sujeito não pode usar a atenção de maneira eficiente para enfrentar tarefas externas, uma vez que precisa dela para restaurar sua "ordem interior subjetiva". No entanto, as emoções positivas, exemplificadas pelo autor como felicidade, força ou alerta são estados que ele denomina como de "negaentropia psíquica", ou seja, uma entropia negativa na qual o sujeito não precisa de atenção para refletir sobre si mesmo (como pena de si mesmo), facilitando para que a energia psíquica possa fluir livremente para a tarefa que se pretende investir.

Um exemplo de estudo sobre aprendizagem e prática musical que utiliza a experiência de fluxo, e que favorece o reconhecimento da emoção como um componente essencial dessa experiência, é o trabalho de Addessi e Pachet (2007). Os autores desenvolveram um estudo com crianças entre 3 e 5 anos sobre o uso de sistemas musicais interativos-reflexivos e utilizaram a teoria do fluxo como um elemento de análise nas interações vivenciadas pelas crianças. As atividades foram gerenciadas por meio do uso de um programa (Continuator) conectado a um teclado. A partir de onze variáveis definidas com base na teoria de Csikszentmihalyi - excitação, envolvimento, atenção direcionada, concentração, retorno imediato, controle da situação, motivação intrínseca, mudança da percepção do tempo, objetivos claros, prazer e socialização - os autores centraram suas observações. O estado de fluxo foi verificado nas interações musicais das crianças por meio das experiências desenvolvidas individualmente e na relação com colegas durante a realização das atividades musicais. Como resultado, foi possível observar que, mesmo com crianças muito pequenas, é possível uma imersão profunda numa atividade musical desafiadora, instigante, na qual a emoção é um fator presente, desde que considerada ao alcance das habilidades das crianças. 
Outro exemplo de estudo que auxilia a reflexão sobre a emoção como conteúdo da experiência na condução para o fluxo, é o estudo de O’Neill (1999). A autora procurou relacionar quantidade de tempo de estudo com o reportamento para a experiência de fluxo, em jovens com faixa etária entre 12 e 16 anos e níveis distintos de performance. Com base nos resultados da pesquisa, a autora pôde verificar que os contextos avaliativos contribuem para a redução da experiência de fluxo especialmente em alunos considerados menos habilidosos na prática instrumental. Assim, por meio da análise dos resultados, a autora adverte aos docentes envolvidos no ensino instrumental para que procurem diferentes estratégias para motivar os estudantes que apresentam mais dificuldades, como condição de lhes assegurar a qualidade intrínseca de suas experiências musicais.

\subsection{Metas}

As metas são descritas por Csikszentmihalyi (1999, 1992) como os elementos que focalizam a energia psíquica do indivíduo. São geralmente ordenadas (de forma hierárquica) e criam a ordem na experiência realizada. Csikszentmihalyi explica que são as metas buscadas pelos indivíduos que

46 determinam o seu self. Neste sentido, o sujeito que não desenvolve um conjunto de metas sólidas e claras terá dificuldades para desenvolver um self coerente. Assim o autor ainda relaciona as metas investidas pelo indivíduo e a relação destas com a auto-estima, na dependência das expectativas e do sucesso. Ele explica: "Uma pessoa pode desenvolver uma baixa auto-estima porque estabelece metas elevadas demais, ou porque alcança muito poucos sucessos" (Csikszentmihalyi, 1999, p. 31).

Observando o conteúdo da experiência e sua vinculação à utilização das metas, Troum (2008) discutiu a prática deliberada de músicos instrumentistas mediada por meio do estabelecimento de metas e estratégias. A autora apontou para os componentes que conduzem à experiência do fluxo e os componentes vivenciados durante o fluxo como elementos que se encontram em estreita relação com o processo da prática musical de músicos com alta performance e 
com o desenvolvimento da expertise (cita especialmente a motivação intrínseca, o uso de metas e a concentração). A autora estabeleceu também algumas orientações para que o professor possa efetivamente auxiliar no progresso do estudo do aluno. Dentre suas recomendações, ela coloca como primeiro passo o reconhecimento das necessidades intrínsecas do estudante e a adequação das condições para sua prática individual. Segundo a autora, a identificação e a orientação de objetivos intrínsecos são qualitativamente mais significativos que o estabelecimento de objetivos extrínsecos, como os concursos ou recitais.

Outro exemplo de pesquisa na qual foram relacionados o estabelecimento de metas e o reportamento para a experiência do fluxo, foi desenvolvido por Custodero (2006). Esta autora procurou investigar, por meio de diferentes estudos (Iongitudinais ou centrados em grupos de idades específicas), o processo da experiência de fluxo em pesquisas que envolveram crianças na faixa etária de 0 a 11 anos. Utilizando-se de observações sistemáticas, nas quais focalizou as interações das crianças com a música, a autora pôde indicar três princípios para a condução das atividades musicais: a) o cuidado para com o estabelecimento de desafios apropriados e a manutenção dos mesmos, observando, portanto, a utilização de metas; b) o reconhecimento da autonomia dos alunos; e c) a atenção para com o envolvimento das crianças em atividades próprias da cultura da infância, também vinculadas à natureza socializadora da atividade musical.

Griffin (2008), por sua vez, utilizou a ênfase no estabelecimento de metas para aprimorar um método moderno de ensino de teclado, de aplicação em aulas de música para alunos da escola regular. $\mathrm{O}$ autor utilizou-se dos estudos de Csikszentmihalyi, Gardner, Goleman e Elliot como alicerce teórico de sua proposta pedagógica e de sua investigação. A partir de uma survey, o autor buscou levantar dados coletados junto a 100 alunos participantes que comprovassem a aquisição de diferentes habilidades musicais e extra-musicais dos envolvidos, bem como que identificassem componentes psicológicos sobre a qualidade do engajamento desses alunos nas atividades realizadas. Dentre os resultados positivos apontados pelo autor, vinculados à teoria do fluxo, 
especialmente aos conteúdos das metas, pode-se apontar a constatação da coerente organização do método a respeito da dosagem apropriada das dificuldades (metas e objetivos claros), demonstrando que tal cuidado favoreceu significativamente o progresso técnico/musical de $89 \%$ dos participantes. Como habilidades não musicais desenvolvidas pelos alunos, o autor cita o aumento da capacidade de concentração - elemento constituinte da experiência do fluxo indicada por $72 \%$ dos participantes. O autor traz também muitos outros resultados analisados com base em outras teorias e aponta, enfim, como um dos dados principais de sua experiência, o desenvolvimento das inteligências interpessoal e intrapessoal, discutidas na teoria de Gardner.

\subsection{Operações mentais cognitivas}

Por fim, as operações mentais cognitivas, realizadas por meio do pensamento, são os componentes da experiência de fluxo que ordenam a atenção e produzem a seqüência significativa da experiência vivenciada. Assim, para ordenar e executar as operações mentais de forma intensa (ou profunda), o sujeito tem a necessidade de concentrar sua atenção, pois, conforme esclarece o

48 autor, sem um foco definido, a consciência encontra-se normalmente num estado de caos, ou seja, a desordem de informações é uma condição normal da mente, na qual surgem os pensamentos aleatórios, sem seqüência lógica, dispersos. A concentração, portanto, exige um esforço do sujeito, uma espécie de controle sobre a vida psíquica. Tal estado será mais difícil e exigirá um esforço maior do sujeito se contrariar as emoções e a motivação. Para o autor, portanto, focalizar a mente quando o indivíduo está motivado torna-se fácil, mesmo que se encontrem dificuldades objetivas.

As operações mentais cognitivas são, portanto, um conteúdo da experiência de fluxo, no qual o fator concentração é um elemento essencial a ser considerado. Este elemento, por sua vez, conduz a observação de outro dado vinculado ao fluxo, que é a perda da noção de tempo. 
Araújo e Pickler (2008), em pesquisa realizada no Brasil, procuraram discutir a motivação na prática musical de estudantes de nível universitário como elemento que possibilita a experiência do "estado de fluxo", focalizando especialmente aspectos que geram a concentração na prática musical dos indivíduos. O objetivo geral das pesquisadoras foi investigar os processos motivacionais que conduzem a prática de estudantes de música e que favorecem tal experiência. Para tanto, as autoras discutiram - a partir de dados coletados por meio de um survey (estudo de levantamento) realizado com estudantes da graduação em música - algumas etapas vinculadas a esta experiência que geram a concentração, como o estabelecimento de metas; as reflexões sobre a condução do processo de aprendizagem; e a incidência de fatores motivacionais intrínsecos e extrínsecos, entre outros. Com os resultados as autoras observaram que, embora alguns participantes não demonstrem vivenciar o "estado de fluxo" em suas práticas musicais, a grande maioria dos respondentes indica a incidência de situações que conduzem freqüentemente a este processo, como a perda da noção de tempo, a sensação de bem estar, a vontade de superar desafios, a preferência por determinado repertório, dentre outras.

Silva (2008), por fim, buscou indicar, por meio de uma metodologia interdisciplinar de trabalho didático, possibilidades metodológicas de condução para uma oficina de performance musical. Dentro de sua proposta, o autor procurou interferir e auxiliar nos fatores extrínsecos e intrínsecos da experiência performática de forma a gerar conhecimentos e competências que possibilitem ao músico uma aproximação com a experiência de fluxo, vinculada, portanto a um estado de concentração.

\section{Considerações finais}

O estudo ou prática musical, em diferentes níveis, pode ser uma atividade ótima a partir da qualidade da experiência vivenciada. Neste sentido, boas experiências podem assegurar um investimento e uma persistência do sujeito na ação. Assim, para educadores, performers, enfim indivíduos envolvidos no 
exercício da prática musical, a teoria do fluxo traz elementos específicos para a condução e compreensão de uma experiência significativa do fazer musical.

A teoria desenvolvida por Csikszentmihalyi, considerada como referencial em muitos trabalhos já desenvolvidos sobre motivação e música, favorece a observação de um dos enfoques principais constatados nos estudos já realizados: a centralização na qualidade da experiência realizada durante a prática musical. Esta abordagem auxilia a compreensão de componentes importantes do processo de aprendizagem, como o prazer e a alegria gerados durante a atividade que, por sua vez, conduzem os estudantes à persistência nos estudos musicais. Dentre os principais aspectos abordados e discutidos nos trabalhos aqui revisados encontram-se: a) o estabelecimento de metas; b) o cuidado para com a qualidade dos desafios apresentados; c) o direcionamento da aprendizagem de acordo com as capacidades dos alunos; d) o cuidado com os aspectos emocionais do processo, e) a priorização de condições extrínsecas e intrínsecas que gerem a concentração.

As experiências de fluxo vivenciadas continuamente, conforme aponta Csikszentmihalyi (1999), podem, por sua vez, gerar indivíduos com personalidade autotélica. Silva (2007) defende que o individuo autotélico, devido à qualidade de suas experiências e pela intensidade de suas ações e investimentos nas atividades, podem registrar estados emocionais positivos com mais freqüência que sujeitos não autotélicos. Neste sentido, a prática musical calcada em fatores motivacionais intrínsecos e gerenciada num processo de fluxo, favorece o desenvolvimento da personalidade autotélica que, de acordo com Csikszentmihalyi (1999), faz com que o indivíduo torne-se mais concentrado em suas atividades, com a auto-estima mais elevada e que se sinta mais satisfeito com suas ações.

Os sujeitos criativos, conforme aponta Silva (2007), freqüentemente também são autotélicos, e possuem uma "aparentemente inesgotável energia psíquica” (Csikszentmihalyi, 1999, p. 120). Tal energia psíquica favorece a busca pela novidade, pela surpresa, enfim pela ultrapassagem de limites por meio de uma atitude de interesse pelo desafio, que favorece e melhora a qualidade de vida dos indivíduos em geral. Para o autor, portanto o primeiro passo é 
desenvolver o hábito da concentração e em seguida transferir a energia psíquica na tarefa selecionada. Para os interessados no aprofundamento dos estudos sobre prática, ensino e aprendizagem musical, esta orientação pode, enfim, favorecer um envolvimento efetivo e desafiador para que a qualidade da experiência musical seja realmente significativa.

\section{Referências:}

ABRANTES, S.; GOUVEIA, L. M. B. Será que os jogos são eficientes para ensinar? Um estudo baseado na experiência do fluxo. Site do Instituto Politécnico de Viseu, 2007. Disponível em:

$<$ http://www2.ufp.pt/ /mbg/com/salbg_challenges07.pdf>. Acesso em: 17 jul. 2008.

ADDESSI, A. R.; PACHET, F. Sistemas musicais interativos-reflexivos para educação musical. In: Cognição e Artes, Curitiba, DeArtes UFPR, v. 2, n. 1, p. 62-72, 2007.

ARAÚJO, R. C.; PICKLER, L. Um estudo sobre motivação e estado de fluxo na execução musical. In: Anais do IV Simpósio de Cognição e artes musicais, 2008. Disponível em: <http://www.fflch.usp.br/dl/simcam4/anais_simcam4.htm>. Acesso em: 15 jul. 2008.

BZUNEK, José A. A motivação do aluno: aspectos introdutórios. In: BORUCHOVITCH, E.; BZUNECK, J. A. A motivação do aluno: Contribuições da Psicologia Contemporânea. Petrópolis: Vozes, 2001.

CAMPEIZ, E. C. F.; VOLP, C. M. Dança criativa: a qualidade da experiência subjetiva. Revista Motriz, v. 10, n. 3, p. 167-172, set.-dez. 2004.

COSTA, E. R.; BORUCHOVITCH, E. A. A auto-eficácia e a motivação para aprender: considerações para o desempenho escolar dos alunos. In: AZZI, R. G.; POLYDORO, S. A. J. (Orgs.). Auto-eficácia em diferentes contextos. Campinas: Alínea, 2008. p. 87-110.

CUSTODERO, Lori A. Buscando desafios, encontrando habilidades: a experiência de fluxo e a educação musical. In: ILARI, Beatriz (Org.). Em busca da mente musical. Curitiba: Editora da UFPR, 2006. p. 381-399.

CSIKSZENTMIHALYI, Mihaly. Good Business: Flow, Leadership and Making of Meaning. New York: Viking, 2003.

- A descoberta do fluxo. Psicologia do envolvimento com a vida cotidiana. Rio de Janeiro: Rocco, 1999.

Creativity: Flow and the Psychology of Discovery and Invention. New York: Harper Collins, 1996. 
. A psicologia da felicidade. São Paulo: Saraiva, 1992.

. Flow: The psychology of Optimal Experience. New York: Harper \& Row, 1990.

DECI, E. L.; RYAN, R. M. The "What" and "Why" of Goal Pursuits: Human Needs and the Self-Determination of Behavior. Psychological Inquiry, v. 11, n. 4, p. 227-268, 2000.

GRIFFIN, Michael. Creating Emotional Intelligence: Opportunities for General Music Students in the Keyboard Laboratory. In: $28^{\text {th }}$ ISME World Conference, 2008. In: Anais... Bologna, 2008. p. 113-117.

O'NEILL, Suzan. Flow theory and the development of musical performance skills. Bulletin of the council for Research in Music Education. n. 141, p. 129-134, 1999.

SILVA, Abel. Oficinas de performance musical: uma metodologia interdisciplinar para uma abordagem complexa da performance musical. In: Anais do IV Simpósio de Cognição e Artes Musicais, 2008. Disponível em:

<http://www.fflch.usp.br/dl/simcam4/anais_simcam4.htm>. Acesso em: 15 jul. 2008.

SILVA, José, A. A dinâmica da felicidade. Psique-Ciência e Vida, v.1, p. 53-59, 2007.

TROUM, Julie. Self-regulated deliberate flow: A metacognitive goal-girected práxis toward musical practice. 28 ${ }^{\text {th }}$ ISME World Conference, 2008. In: Anais.... Bologna, 2008. p. 637-638.

VOLP, C. M.; DEUTSCH, S.; SHWARTZ, G. M. Por que dançar? Um estudo comparativo. Revista Motriz, v. 1, n.1, p. 52-58, jun. 1995.

Rosane Cardoso Araújo: rosanecardoso@ufpr.br

Artigo recebido e aprovado em 15 de setembro de 2008 